\title{
Cardiovascular disease risk factors as predictors of Type 2 (non-insulin-dependent) diabetes mellitus in elderly subjects*
}

\author{
L. Mykkänen, J.Kuusisto, K. Pyörälä, M. Laakso \\ Department of Medicine, University of Kuopio, Kuopio, Finland
}

\begin{abstract}
Summary. Risk factors measured in a cross-sectional study in subjects aged $65-74$ years living in eastern Finland were correlated with the risk of developing diabetes 3.5 years later. Sixty-nine of 892 initially non-diabetic subjects developed diabetes during the follow-up. Subjects who subsequently developed diabetes had multiple adverse changes in risk factor levels before the diagnosis of diabetes. Subjects who developed diabetes had higher body mass index and waist-hip ratio as well as higher levels of fasting and $2-h$ plasma glucose and insulin and higher prevalence of family history of diabetes than those who remained healthy. Furthermore, prevalence of hypertension and levels of diastolic blood pressure and total triglycerides were higher and HDL cholesterol lower among subjects who developed diabetes than among those who remained healthy. The highest risk of developing diabetes was associated with impaired glucose tolerance (World Health Organisation criteria) (odds ratio $=9.8,95 \%$ confidence interval $=6.1-5.8$ ). The risk of developing diabetes was $3.7(3.2-6.1)$ among subjects in the highest quartile of 2 -h insulin distribution, $3.5(2.0-6.1)$ in
\end{abstract}

those with triglycerides greater than $2.5 \mathrm{mmol} / 1,2.7$ (1.5-4.6) in those with waist-hip ratio greater than $1.0,2.5(1.5-4.4)$ in those with $\mathrm{HDL}$ cholesterol less than $1.0 \mathrm{mmol} / \mathrm{l}, 2.1(1.2-$ $3.6)$ in those with body mass index greater than $30 \mathrm{~kg} / \mathrm{m}^{2}, 1.9$ (1.1-3.3) among those in the highest quartile of fasting insulin distribution, $1.8(1.0-3.1)$ in those having hypertension, and $1.7(1.0-2.9)$ in those with a family history of diabetes. The risk of diabetes increased by clustering of risk factors related to insulin resistance (impaired glucose tolerance, triglycerides $>2.5 \mathrm{mmol} / \mathrm{l}$, HDL cholesterol $<1.0$, hypertension) so that the risk was 3.6 -fold in those having one risk factor and 59 -fold in those having all four risk factors compared to subjects having no risk factors. In conclusion, cardiovascular risk factors related to insulin resistance are predictors of diabetes in the elderly.

Key words: Type 2 (non-insulin-dependent) diabetes mellitus, impaired glucose tolerance, incidence study, obesity, hypertension, lipids, lipoproteins, plasma insulin, elderly.
Prospective studies have shown that in middle-aged subjects high plasma glucose level [1-3] and impaired glucose tolerance (IGT) [4-6] are among the best predictors of Type 2 (non-insulin-dependent) diabetes mellitus. Subjects who subsequently develop diabetes also have high plasma insulin levels $[2,3,7-9]$ and they are insulin resistant [9]. Furthermore, middle-aged pre-diabetic subjects have elevated blood pressure [10-12], hypertriglyceridaemia [10-13], and low HDL cholesterol levels [11] even before the onset of clinical diabetes. Due to these multiple adverse changes in the cardiovascular risk factor profile pre-diabetic subjects are likely to be at an increased risk for atherosclerosis [11].

\footnotetext{
* This study was presented at the 28 th Annual Meeting of the European Association for the Study of Diabetes in Prague, Czechoslovakia, 8-11 September 1992
}

Although the prevalence of diabetes increases markedly in the elderly [14] information about the pre-diabetic state and risk factors for diabetes in the elderly are scarce. There are no data available on the natural history and predictive value of IGT for future risk of diabetes in the elderly. Furthermore, it is not known whether hyperinsulinaemia also predicts diabetes in the elderly. Nevertheless, the Rancho Bernardo study from California [12] has shown that a less favourable cardiovascular risk factor profile precedes the diagnosis of both Type 2 diabetes and IGT in elderly subjects. However, it is not known whether clustering of cardiovascular risk factors is associated with an increased risk of developing diabetes in the elderly. To investigate these questions risk factors measured in a cross-sectional population-based study in subjects aged $65-74$ years living in eastern Finland were correlated with the risk of developing diabetes 3.5 years later. 
Table 1. Comparison of glucose tolerance status of non-diabetic subjects at baseline in 1986-1988 and follow-up status 3.5 years later: Kuopio, eastern Finland, 1986-1991

\begin{tabular}{|c|c|c|c|c|}
\hline \multirow{2}{*}{$\begin{array}{l}\text { Glucose tolerance } \\
\text { status 1986-1988 }\end{array}$} & \multicolumn{3}{|c|}{ Glucose tolerance status at 3.5 year follow-up } & \multirow[b]{2}{*}{ Total } \\
\hline & $\begin{array}{l}\text { Normal glucose } \\
\text { tolerance }\end{array}$ & $\begin{array}{l}\text { Impaired glucose } \\
\text { tolerance }\end{array}$ & Diabetes & \\
\hline $\begin{array}{l}\text { Men } \\
\text { Normal glucose tolerance (\%) } \\
\text { Impaired glucose tolerance (\%) }\end{array}$ & $\begin{array}{l}79.1(200) \\
30.0(21)\end{array}$ & $\begin{array}{l}16.6(42) \\
42.9(30)\end{array}$ & $\begin{array}{r}4.3(11) \\
27.1(19)\end{array}$ & $\begin{array}{l}(253) \\
(70)\end{array}$ \\
\hline $\begin{array}{l}\text { Women } \\
\text { Normal glucose tolerance }(\%) \\
\text { Impaired glucose tolerance }(\%)\end{array}$ & $\begin{array}{l}77.5(338) \\
38.3(51)\end{array}$ & $\begin{array}{l}20.2(88) \\
39.8(53)\end{array}$ & $\begin{array}{r}2.3(10) \\
21.8(29)\end{array}$ & $\begin{array}{l}(436) \\
(133)\end{array}$ \\
\hline $\begin{array}{l}\text { Sexes combined } \\
\text { Normal glucose tolerance }(\%) \\
\text { Impaired glucose tolerance }(\%)\end{array}$ & $\begin{array}{l}78.1(538) \\
35.5(72)\end{array}$ & $\begin{array}{l}18.9(130) \\
40.9(83)\end{array}$ & $\begin{array}{r}3.0(21) \\
23.6(48)\end{array}$ & $\begin{array}{l}(689) \\
(203)\end{array}$ \\
\hline
\end{tabular}

\section{Subjects and methods}

\section{Subjects}

The baseline cross-sectional study was conducted in Kuopio, eastern Finland in 1986-1988. The formation [15] and representativeness [16] of the study population have been previously described in detail. The 1300 subjects who participated in the study at baseline were randomly selected from the Kuopio population aged $65-74$ years. The follow-up was performed in 1990-1991, on average 3.5 years (42 \pm 4 months) after the baseline cross-sectional study. After the baseline study 108 subjects died leaving 1192 subjects eligible for follow-up. Eventually 1054 subjects participated in the follow-up giving an overall participation rate of $88 \%$. A total of 159 subjects had diabetes at baseline and three subjects had incomplete oral glucose tolerance test at the follow-up examination and they were excluded from the analyses in this report leaving 323 men and 569 women.

\section{Methods}

Weight and height were measured in light clothing without shoes. Body mass index (BMI) was calculated as weight $(\mathrm{kg})$ divided by height (m) squared and was used as an index of overall adiposity. The waist-hip ratio was used as a measure of body fat distribution. Waist circumference was measured at the level of the umbilicus with the subject standing and breathing normally. Hip circumference was measured at the level of the greatest hip girth. Blood pressure was measured in the supine position with a mercury sphygmomanometer after a 5-min rest. Two readings were taken (interval $1.5 \mathrm{~min}$ ), and the latter one was used in statistical analyses. A subject was defined as having hypertension if systolic blood pressure was $160 \mathrm{~mm} \mathrm{Hg}$ or over, or diastolic blood pressure was $95 \mathrm{~mm} \mathrm{Hg}$ or over, or if he/she was receiving drug treatment for hypertension. Alcohol consumption was determined according to the subject's estimate of the average number of glasses of beer, wine, or other alcoholic drinks ingested per week. In statistical analyses subjects were classified as alcohol users or non-users. Smoking was defined if the subject was a current smoker. Family history of diabetes was regarded positive if one of the parents or siblings had Type 2 diabetes.

Previously known diabetes was considered to be present, if the diagnosis of diabetes had previously been made by a physician. The World Health Organization diagnostic criteria for diabetes were used in the classification of subjects without previously known diabetes [17]. The criteria are as follows: 1) diabetes mellitus, fasting venous plasma glucose $7.8 \mathrm{mmol} / 1$ or above or 2 -h venous plasma glucose $11.1 \mathrm{mmol} / \mathrm{h}$ or above in a $75 \mathrm{~g}$ oral glucose tolerance test (OGTT); 2) impaired glucose tolerance (IGT), fasting venous plasma glucose less than $7.8 \mathrm{mmol} / \mathrm{l}$ and 2 -h venous plasma glucose $7.8-$ $11.1 \mathrm{mmol} / \mathrm{i}$; ) normal glucose tolerance, fasting and 2 -h venous plasma glucose less than $7.8 \mathrm{mmol} / 1$.

\section{Laboratory methods}

Blood samples were taken between 07.30 and 09.30 hours after a 12-h fast. All subjects underwent a 75-g OGTT both in the baseline cross-sectional study and at 3.5 years follow-up. Venous blood samples for glucose and insulin determinations were taken before and $2 \mathrm{~h}$ after the glucose load into chilled tubes and plasma was separated immediately. Plasma glucose was determined by the glucose oxidase method (Glucose \& Stat HGA-1120 analyzer; Daiichi, Kyoto, Japan). Plasma insulin was determined from samples stored at $-70^{\circ} \mathrm{C}$ by a commercial double-antibody solid-phase radioimmunoassay [18] (Phadeseph Insulin RIA 100; Pharmacia Diagnostics AB, Uppsala, Sweden). Serum HDL cholesterol was determined after the precipitation of low-density and very-low-density lipoproteins with dextran sulphate and magnesium chloride [19]. Commercial enzymatic methods were used in the determination of serum cholesterol $[19,20]$ (Monotest; Boehringer Mannheim, Mannheim, FRG) and triglycerides [21] (Peridocrome; Boehringer Mannheim). Commercial control sera were used to standardize the measurements of cholesterol and triglycerides (Seronorm, Seronorm Lipid; Nycomed, Oslo, Norway).

\section{Statistical analysis}

Data analyses were performed with the SPSS/PC + statistical software [22]. The results for continuous variables are given as mean \pm SEM. The Student"s two-tailed $t$-test for independent samples, analysis of covariance (ANCOVA) and chi-square test were used in assessment of the significance of difference between subjects who developed diabetes and subjects who did not. The risk of developing diabetes associated with various risk factors was assessed by calculating odds ratios.

\section{Results}

Of the 892 subjects who participated, 253 men and 436 women had normal glucose tolerance and 70 men and 133 women had IGT at baseline (Table 1). Of the subjects with IGT at baseline $23.6 \%$ developed diabetes during 3.5 years follow-up whereas incidence of diabetes was $3.0 \%$ only among subjects with normal glucose tolerance at baseline. Thus, the overall 3.5 year incidence of diabetes was $7.7 \%$ (69/892).

Table 2 shows baseline demographic characteristics and levels of cardiovascular risk factors in subjects who developed diabetes and in those who remained healthy dur- 
Table 2. Baseline demographic characteristics and cardiovascular risk factors according to diabetes status at 3.5 year follow-up: Kuopio, eastern Finland, 1986-1991

\begin{tabular}{|c|c|c|c|}
\hline & $\begin{array}{l}\text { Developed } \\
\text { diabetes } \\
(n=69)\end{array}$ & $\begin{array}{l}\text { Remained } \\
\text { healthy } \\
(n=823)\end{array}$ & $p$-value \\
\hline$\overline{\text { Sex }(\%, \text { male/female })}$ & $43 / 57(30 / 39)$ & $36 / 64(293 / 530)$ & NS \\
\hline Age (years) & $68.6 \pm 0.3$ & $68.9 \pm 0.1$ & NS \\
\hline Body mass index $\left(\mathrm{kg} / \mathrm{m}^{2}\right)$ & $29.0 \pm 0.5$ & $27.0 \pm 0.1$ & $<0.001$ \\
\hline Waist-hip ratio & $0.95 \pm 0.01$ & $0.92 \pm 0.01$ & $<0.001$ \\
\hline Fasting plasma glucose $(\mathrm{mmol} / \mathrm{l})$ & $6.2 \pm 0.1$ & $5.7 \pm 0.1$ & $<0.001$ \\
\hline 2-h plasma glucose $(\mathrm{mmol} / \mathrm{l})$ & $8.4 \pm 0.2$ & $6.4 \pm 0.1$ & $<0.001$ \\
\hline Fasting plasma insulin (pmol/1) & $127 \pm 8$ & $104 \pm 2$ & $<0.01$ \\
\hline 2-h plasma insulin (pmol/l) & $851 \pm 86$ & $492 \pm 14$ & $<0.001$ \\
\hline Total triglycerides (mmol/l) & $2.22 \pm 0.14$ & $1.66 \pm 0.02$ & $<0.001$ \\
\hline Total cholesterol (mmol/ $)$ & $6.48 \pm 0.15$ & $6.59 \pm 0.04$ & NS \\
\hline HDL cholesterol $(\mathrm{mmol} / \mathrm{l})$ & $1.18 \pm 0.04$ & $1.31 \pm 0.01$ & $<0.01$ \\
\hline Systolic blood pressure $(\mathrm{mm} \mathrm{Hg})$ & $159 \pm 3$ & $156 \pm 1$ & NS \\
\hline Diastolic blood pressure $(\mathrm{mm} \mathrm{Hg})$ & $84 \pm 1$ & $81 \pm 1$ & $<0.05$ \\
\hline Hypertensives (\%) & $68.1(47)$ & $54.4(448)$ & $<0.05$ \\
\hline Drug treatment for hypertension $(\%)$ & $34.8(24)$ & $23.6(194)$ & $<0.05$ \\
\hline Current smokers $(\%)$ & $1.4(1)$ & $10.0(82)$ & $<0.05$ \\
\hline Alcohol users (\%) & $29.0(20)$ & $30.5(251)$ & NS \\
\hline Family history of diabetes $(\%)$ & $42.0(29)$ & $30.1(248)$ & $<0.05$ \\
\hline
\end{tabular}

Values are mean $\pm \mathrm{SEM}$

Table 3. Prevalence of adverse levels of risk factors at baseline and risk of developing Type 2 diabetes associated with univariate risk factors: Kuopio, eastern Finland, 1986-1991

\begin{tabular}{llll}
\hline & $\begin{array}{l}\text { Prevalence } \\
\%,(\text { cases }\end{array}$ & Odds ratio & 95\% Confidence interval \\
\hline Impaired glucose tolerance (yes/no) & $22.8(203)$ & $9.85^{\mathrm{c}}$ & $6.14-15.8$ \\
2-h plasma insulin $>621 \mathrm{pmol} / \mathrm{l}$ & $24.9(222)$ & $3.74^{\mathrm{c}}$ & $3.20-6.08$ \\
Total triglycerides $>2.5 \mathrm{mmol} / \mathrm{l}$ & $12.6(112)$ & $3.52^{\mathrm{c}}$ & $2.03-6.11$ \\
Waist-hip ratio $>1.0$ & $16.3(145)$ & $2.66^{\mathrm{c}}$ & $1.54-4.62$ \\
HDL cholesterol $<1.0 \mathrm{mmol} / 1$ & $17.7(158)$ & $2.55^{\mathrm{c}}$ & $1.48-4.39$ \\
Body mass index $>30 \mathrm{~kg} / \mathrm{m}^{2}$ & $20.3(181)$ & $2.10^{\mathrm{b}}$ & $1.21-3.65$ \\
Fasting plasma insulin $>124 \mathrm{pmol} / 1$ & $24.9(222)$ & $1.93^{\mathrm{a}}$ & $1.13-3.31$ \\
Hypertension (yes/no) & $55.5(495)$ & $1.79^{\mathrm{a}}$ & $1.03-3.10$ \\
Family history of diabetes (yes/no) & $31.1(277)$ & 1.68 & $0.99-2.86$ \\
\hline
\end{tabular}

${ }^{a} p<0.05,{ }^{b} p<0.01,{ }^{c} p<0.001$. Odds ratio compares odds for subjects with a risk factor level above the cut-off point to odds for subjects with a risk factor level below the cut-off point; cut-off points for

ing follow-up. Subjects who developed diabetes had higher BMI, waist-hip ratio, and fasting and 2 -h plasma glucose and insulin levels than subjects who remained healthy. Furthermore, total triglyceride level and diastolic blood pressure were higher and HDL cholesterol level was lower among subjects who developed diabetes than among those who did not. In addition, prevalence of hypertension and family history of diabetes were higher and proportion of current smokers was lower among subjects who developed diabetes than among those who remained healthy. Howyever, there were no differences in age, total cholesterol or systolic blood pressure levels, or proportion of alcohol users between subjects who developed diabetes and subjects who did not. These differences in risk factor levels between subjects who developed diabetes and those who did not persisted except the differences in HDL cholesterol and diastolic blood pressure which disappeared after the adjustment for BMI and waist-hip ratioin ANCOVA (data not shown). Adjustment for BMI, waist-hip ratio and fasting plasma glucose abolished all the differences except in the 2-h plasma insulin and total triglyceride levels (data not fasting and 2-h plasma insulin levels were lower limits of highest quartiles; odds ratios were calculated by Mantel-Haenszel chisquare test

shown). However, adjustment for BMI, waist-hip ratio and fasting plasma insulin abolished only the differences in HDL cholesterol and diastolic blood pressure levels between subjects who developed diabetes and those who remained healthy, but not differences in other risk factor levels (data not shown).

Table 3 shows the prevalence of adverse levels of risk factors at baseline and the risk of developing diabetes associated with univariate risk factors. Prevalence of adverse levels of univariate risk factors ranged from $12.6 \%$ for total triglyceride level over $2.5 \mathrm{mmol} / \mathrm{l}$ to $55.5 \%$ for hypertension. The risk of developing diabetes was assessed by calculating odds ratios. Odds ratio compared odds for subjects with a risk factor level above the cut-off point to odds for subjects with a risk factor level below the cut-off point. The highest risk of diabetes was associated with IGT. Altogether $22.8 \%$ of participants had IGT and they had a 9.8-fold risk of developing diabetes compared to subjects with normal glucose tolerance. The risk of diabetes associated with other risk factors was markedly lower compared to the risk associated with IGT. The risk 
Table 4. Prevalence of clusters of impaired glucose tolerance (IGT), hypertriglyceridaemia (hyper TG), low HDL-cholesterol (low HDL), and hypertension (HT), risk of developing Type 2 diabetes in various clusters of these risk factors, and plasma insulin level in various risk factor clusters: Kuopio, eastern Finland, 1986-1991

\begin{tabular}{|c|c|c|c|c|}
\hline & $\begin{array}{l}\text { Prevalence } \\
\% \text {, (cases) }\end{array}$ & Odds ratio & $\begin{array}{l}95 \% \text { Confidence } \\
\text { interval }\end{array}$ & $\begin{array}{l}\text { 2-h plasma insulin } \\
\text { (pmol/l) }\end{array}$ \\
\hline No risk factors & $30.2(269)$ & 1.00 & - & $323 \pm 11$ \\
\hline $\begin{array}{l}\text { Clusters of two risk factors } \\
\text { Low HDL and HT } \\
\text { Hyper TG and HT } \\
\text { Hyper TG and low HDL } \\
\text { IGT and HT } \\
\text { IGT and low HDL } \\
\text { IGT and hyper TG }\end{array}$ & $\begin{array}{l}10.3(92) \\
8.1(72) \\
6.1(54) \\
15.7(140) \\
5.4(48) \\
4.6(41)\end{array}$ & $\begin{array}{l}7.40 \\
9.32 \\
10.3 \\
11.7 \\
17.9 \\
28.2\end{array}$ & $\begin{array}{r}3.07-17.8 \\
3.80-22.8 \\
4.04-26.5 \\
5.28-26.0 \\
7.14-44.9 \\
11.1-71.7\end{array}$ & $\begin{array}{c}835 \pm 68 \\
974 \pm 89 \\
975 \pm 108 \\
903 \pm 52 \\
1152 \pm 111 \\
1200 \pm 127\end{array}$ \\
\hline $\begin{array}{l}\text { Clusters of three risk factors } \\
\text { Hyper TG and low HDL and HT } \\
\text { IGT and low HDL and HT } \\
\text { IGT and hyper TG and HT } \\
\text { IGT and hyper TG and low HDL }\end{array}$ & $\begin{array}{l}3.7(33) \\
3.4(30) \\
3.5(31) \\
2.5(22)\end{array}$ & $\begin{array}{l}12.2 \\
28.5 \\
30.6 \\
39.1\end{array}$ & $\begin{array}{l}4.32-34.6 \\
10.4-78.0 \\
11.3-82.8 \\
13.1-117\end{array}$ & $\begin{array}{l}1077 \pm 151 \\
1202 \pm 155 \\
1210 \pm 153 \\
1394 \pm 209\end{array}$ \\
\hline $\begin{array}{l}\text { Cluster of four risk factors } \\
\text { IGT and hyper TG and } \\
\text { low HDL and HT }\end{array}$ & $1.6(14)$ & 58.7 & $16.0-215$ & $1520 \pm 289$ \\
\hline
\end{tabular}

Odds ratio compares odds for subjects with a stated risk factor cluster to odds for subjects with no risk factors

Table 5. The number of metabolic disorders at follow-up in relation to baseline 2-h insulin concentration: Kuopio, eastern Finland, 1986-1991

\begin{tabular}{|c|c|c|c|c|c|}
\hline & \multicolumn{4}{|c|}{ Quartiles of 2 -h insulin at baseline } & \multirow[t]{2}{*}{$p$-value } \\
\hline & $\bar{I}$ & II & III & IV & \\
\hline $\begin{array}{l}\text { Entire study population }(n) \\
\text { Mean number of disorders } \\
\geq 2 \text { disorders }(\%)\end{array}$ & $\begin{array}{l}(223) \\
0.51 \pm 0.04 \\
6.3(14)\end{array}$ & $\begin{array}{l}(224) \\
0.58 \pm 0.04 \\
6.3(14)\end{array}$ & $\begin{array}{l}(223) \\
0.82 \pm 0.05^{\mathrm{c}} \\
12.6(28)^{\mathrm{a}}\end{array}$ & $\begin{array}{l}(222) \\
1.13 \pm 0.06^{c} \\
26.6(59)^{\mathrm{c}}\end{array}$ & $\begin{array}{l}<0.001 \\
<0.001\end{array}$ \\
\hline $\begin{array}{l}\text { Subjects with no disorders at baseline }(n) \\
\text { Mean number of disorders } \\
\geq 2 \text { disorders }(\%)\end{array}$ & $\begin{array}{l}(78) \\
0.18 \pm 0.04 \\
0\end{array}$ & $\begin{array}{l}(79) \\
0.18 \pm 0.04 \\
0\end{array}$ & $\begin{array}{l}(77) \\
0.26 \pm 0.05 \\
0\end{array}$ & $\begin{array}{l}(78) \\
0.42 \pm 0.06^{b} \\
3.8(3)\end{array}$ & $\begin{array}{l}0.002 \\
0.019\end{array}$ \\
\hline
\end{tabular}

${ }^{\mathrm{a}} p<0.05,{ }^{\mathrm{b}} p<0.01,{ }^{\mathrm{c}} p<0.001$ ( $t$-test or chi-square test; II, III, or $I$ insulin quartile vs I insulin quartile). $p$-value for ANOVA or chi-square test over insulin quartiles. In the entire study population 2 -h insulin levels in the various quartiles were I, $<252 \mathrm{pmol} /$; II, 252-391 pmol/l; III, 391-621 pmol/l; IV, $\geq 621 \mathrm{pmol} / \mathrm{l}$. In subjects

of diabetes was 3.7 among subjects in the highest quartile of 2-h plasma insulin distribution, 3.5 in those with total triglyceride level over $2.5 \mathrm{mmol} / 1,2.7$ in those with waisthip ratio over 1.0, 2.5 in those with HDL cholesterol level less than $1.0 \mathrm{mmol} / \mathrm{l}, 2.1 \mathrm{in}$ those with BMI over $30 \mathrm{~kg} / \mathrm{m}^{2}$, and less than two among subjects in the highest quartile of fasting plasma insulin distribution, in those with hypertension, and in those with a family history of diabetes.

Further analyses were made to investigate whether clustering of risk factors related to insulin resistance (IGT, hypertriglyceridaemia, low HDL cholesterol level, hypertension) was associated with an increased risk of developing diabetes. Altogether $30.2 \%$ of subjects did not have any of these risk factors, $69.7 \%$ had one risk factor, $28.8 \%$ had two risk factors, $8.3 \%$ had three risk factors, and only $1.6 \%$ had four risk factors. The group with no risk factors was chosen to serve as a reference group with the risk of diabetes equal to one (Table 4). Odds ratios for developing diabetes compared odds for subjects with a stated risk factor cluster to odds for subjects with no risk factors. The risk of diabetes increased by escalating the number of risk factors so that the risk was 3.6 in those having one risk fac- with no disorders at baseline 2 -h insulin levels in the various quartiles were I, $211 \mathrm{pmol} / 1 ; \mathrm{II}, 211-319 \mathrm{pmol} / \mathrm{i} ; \mathrm{II}, 319-432 \mathrm{pmol} / \mathrm{l} ; \mathrm{IV}$, $\geq 432 \mathrm{pmol} / 1$. Metabolic disorders included hypertriglyceridaemia, low HDL cholesterol level, and hypertension

tor, 7.1 in those having any two risk factors, 14.7 in those having any three risk factors, and 58.7 in those having all four risk factors (IGT, hypertriglyceridaemia, low HDL cholesterol, and hypertension) (Fig. 1). The level of 2-h plasma insulin level was parallel to the increase in risk of diabetes so that the 2 -h insulin level was $323 \mathrm{pmol} / \mathrm{l}$ among subjects with no risk factors who also had the lowest risk of diabetes, $606 \mathrm{pmol} / 1$ in those with one risk factor, $836 \mathrm{pmol} / \mathrm{l}$ in those with two risk factors, $1026 \mathrm{pmol} / \mathrm{l}$ in those with three risk factors, and $1520 \mathrm{pmol} / \mathrm{l}$ in subjects having all four risk factors and also the highest risk of diabetes (Fig. 1).

Among clusters of two risk factors, there was marked variability in odds ratios between clusters. Combination of IGT and hypertriglyceridaemia was a four-fold better predictor of diabetes incidence than a combination of low HDL cholesterol and hypertension. Again, the level of 2-h insulin was parallel to the increase in the risk of diabetes. Among clusters of three risk factors those including IGT were associated with a two-three-fold risk of diabetes compared to clusters of hypertriglyceridaemia, low HDL cholesterol and hypertension. 
Table 6. Age-adjusted baseline 2-h insulin concentrations ( $\mathrm{pmol} / \mathrm{l}$ ) by the number of metabolic disorders at baseline and at follow-up: Kuopio, eastern Finland, 1986-1991

\begin{tabular}{lllll}
\hline $\begin{array}{l}\text { Number of meta- } \\
\text { bolic disorders } \\
\text { at baseline }\end{array}$ & $\begin{array}{l}\text { Number of metabolic disorders at } \\
\text { follow-up }\end{array}$ & $p$-value \\
\cline { 2 - 4 } & 0 & 1 & $\geq 2$ & \\
\hline 0 & $352(234)$ & $451(75)^{\mathrm{b}}$ & $726(3)^{\mathrm{a}}$ & 0.001 \\
1 & $471(108)$ & $517(289)$ & $555(30)$ & 0.468 \\
$\geq 2$ & $677(16)$ & $719(53)$ & $954(82)$ & 0.068 \\
\hline
\end{tabular}

In two-way ANOVA the 2-h insulin level was significantly $(p<0.001)$ associated with the number of disorders both at followup and at baseline. There was no significant interaction between the follow-up and baseline number of disorders. ${ }^{a} p<0.05,{ }^{b} p<0.01$ (ANOVA; 1 or $\geq 2$ disorders vs no disorders). ${ }^{\circ} p$-value for ANOVA over the follow-up disorder categories within each baseline disorder category. Values in parenthesis are $n$. Metabolic disorders included hypertriglyceridaemia, low HDL cholesterol level, and hypertension

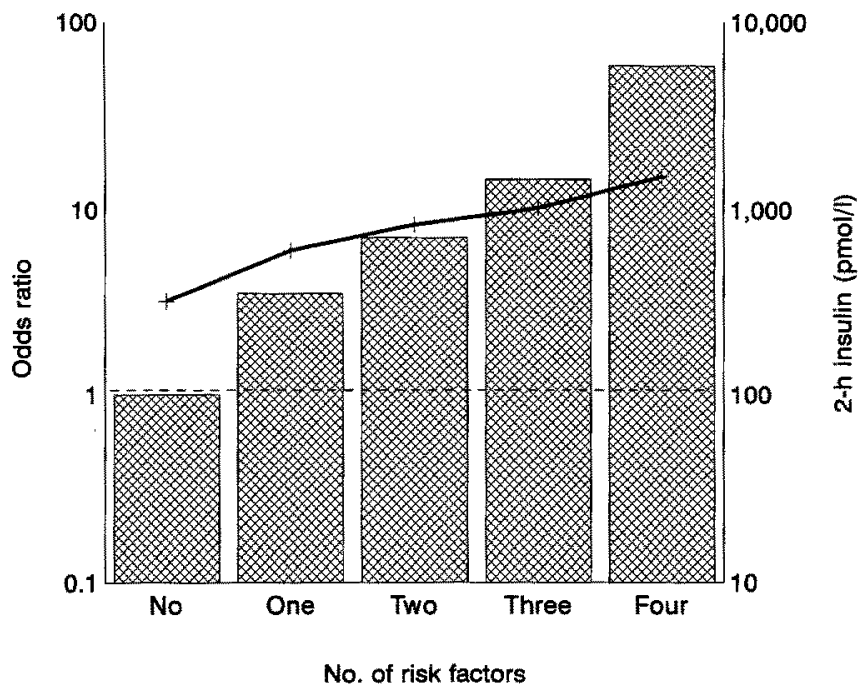

Fig.1. Risk of diabetes (bars, left $y$-axis) and 2-h plasma insulin levels (line, right $y$-axis) by escalating number of risk factors including impaired glucose tolerance (IGT, WHO criteria), hypertriglyceridaemia (total triglycerides $>2.5 \mathrm{mmol} / \mathrm{l}$ ), low HDL cholesterol level (HDL cholesterol $<1.0 \mathrm{mmol} / 1$ ), and hypertension. Odds ratio compares odds for subjects with one, two, three, or four risk factors to odds for subjects with no risk factors. Both $y$-axes are in logarithmic scale

To investigate whether high baseline insulin levels were associated with clustering of metabolic disorders at follow-up we divided the study population into quartiles of baseline 2- $h$ insulin concentrations and calculated the number of metabolic disorders including hypertriglyceridaemia, low HDL cholesterol level, and hypertension at follow-up (Table 5). The mean number of disorders at follow-up increased with quartiles of baseline 2-h insulin concentrations. At follow-up, subjects with baseline insulin levels in the third quartile had two-fold and those with baseline insulin levels in the fourth quartile had four-fold increased prevalence of multiple disorders compared to subjects in the lowest insulin quartile. Among subjects with no disorders at baseline, all those who had multiple disorders at follow-up were in the highest insulin quartile. Because the number of subjects who developed multiple disorders during follow-up was small among subjects with no disorders at baseline, we stratified the number of disorders at follow-up by the number at baseline and analysed 2-h insulin levels for the entire study population (Table 6). High baseline 2-h insulin concentrations were significantly $(p<0.001$, two-way ANOVA) associated with the risk of having multiple disorders at followup.

The analyses of the association of baseline insulin levels and the number of metabolic disorders at follow-up were also performed separately in subjects with normal glucose tolerance and in subjects with IGT at baseline (data not shown). Both in subjects with normal and impaired glucose tolerance, the mean number of metabolic disorders and the number of multiple disorders at followup increased with quartiles of baseline 2 -h insulin concentrations similar to the entire study population. Furthermore, high baseline 2-h insulin concentrations were associated with the risk of having multiple disorders at follow-up both in subjects with normal glucose tolerance $(p<0.05$, two-way ANOVA) and in subjects with IGT $(p=0.05)$.

\section{Discussion}

Several prospective studies have shown that IGT predicts the incidence of Type 2 diabetes in middle-aged subjects $[1-4,6]$. The present study extends these observations to an older age group and demonstrates that subjects with IGT have a 10 -fold risk of developing diabetes during 3.5 years follow-up compared to subjects with normal glucose tolerance. Also, plasma glucose levels, hyperinsulinaemia [2,3,6-9] or insulin resistance [9] has been shown to predict subsequent development of diabetes in middleaged subjects. In this report we showed that insulin concentrations predict diabetes in elderly subjects as well. Our study also confirms more atherogenic risk-factor profiles in pre-diabetic subjects compared to those in subjects who remained healthy during follow-up $[11,12]$, but this is the first report of increasing risk of diabetes by escalating the number of risk factors related to insulin resistance (IGT, hypertriglyceridaemia, low HDL cholesterol level, hypertension).

In this elderly population the role of IGT as a predictor of diabetes was marked. More than two thirds of those who developed diabetes during 3.5 years follow-up had IGT at baseline. It has been previously reported that the prevalence of IGT in this population was $17.8 \%$ in men and $19.1 \%$ in women [15] and altogether $22.8 \%$ of subjects who participated in this study had IGT at baseline. Thus, IGT is a common condition in elderly subjects in Finland similar to other elderly populations $[12,14,23]$.

IGT is a very heterogenous state [24]. Several followup studies in middle-aged and younger populations have indicated that about $50 \%$ of IGT subjects revert to normal glucose tolerance, $25 \%$ remain permanently glucose intolerant, and less than $25 \%$ progress to diabetes $[1,4-6]$. However, there are differences between populations in the conversion rates from IGT to diabetes. In middle-aged Caucasian populations the conversion rate is about $15 \%$ 
during a follow-up of 5-10 years $[1,3,4]$, whereas the rate was found to be about $25 \%$ during a 5 -year follow-up of Nauruans and Pima Indians, the two populations with the highest prevalence of diabetes in the world $[5,6]$. In our elderly population the conversion rate to diabetes in subjects with IGT was $23.4 \%$ in 3.5 years, i. e. two-four-fold compared to previous findings in middle-aged Caucasian populations $[1,3,4]$. Thus, our results suggest that IGT is associated with a higher risk of developing diabetes in an elderly than in a middle-aged population.

According to the present and previous results $[11,12]$ subjects who subsequently developed diabetes had multiple adverse changes in risk factor levels before the diagnosis of diabetes. They had elevated glucose and insulin levels [2,3,7-9], hypertriglyceridaemia [10-13], low HDL cholesterol level [11], and elevated blood pressure $[10-12,25]$. Although subjects who developed diabetes were more obese and had higher insulin levels than those who remained healthy, obesity or fasting plasma insulin did not explain these differences in risk factor levels. However, all the differences in risk factor levels, except the differences in 2-h plasma insulin and total triglyceride levels, disappeared after adjustment for BMI, waist-hip ratio and fasting glucose by ANCOVA implying that the differences in 2-h insulin and triglyceride levels between subjects who developed diabetes and who did not were only independent of glucose levels.

Clustering of risk factors related to insulin resistance (IGT, hypertriglyceridaemia, low HDL cholesterol level, and hypertension) was an important predictor of developing diabetes. Indeed, the risk of diabetes increased by the number of risk factors. Furthermore, the 2 -h plasma insulin level parallelled the increase in risk of diabetes suggesting that insulin resistance may be associated with clustering of cardiovascular risk factors. Hyperinsulinaemia and insulin resistance are well-known predictors of Type 2 diabetes $[2,3,6-9]$. Thus, one probable explanation for our finding that clustering of cardiovascular risk factors predicted the development of diabetes is that this clustering of risk factors was more a marker of the degree of insulin resistance than the single insulin concentration by itself. This hypothesis is supported by our finding that high baseline plasma insulin concentrations were associated with the risk of having multiple metabolic disorders at follow-up. Haffner and co-workers [26] also reported recently that elevations of insulin concentration precede the development of numerous metabolic disorders.

It is possible that some cardiovascular risk factors per se are also risk factors for diabetes. For example central obesity, which is a risk factor for both diabetes $[27,28]$ and coronary heart disease $[29,30]$, is characterized by enlarged visceral fat deposits which are sensitive to lipolysis. Increased lipolysis may lead to insulin resistance [31,32] and hypertriglyceridaemia [33, 34]. Furthermore, it has been recently shown that non-obese subjects with high baseline insulin concentrations have an increased incidence of hypertension compared to non-obese subjects with low insulin concentrations [35]. There are also crosssectional data showing that essential hypertension is associated with insulin resistance both in young, lean subjects with normal glucose tolerance [36] and in non-obese middle-aged diabetic subjects [37]. Thus, cardiovascular risk factors have many connections to glucose metabolism.

One of the limitations of our study was that we did not directly measure the degree of insulin resistance in subjects with various clusters of cardiovascular risk factors. However, it has been shown that there is a significant relationship in normal subjects between the plasma insulin response to oral glucose challenge and insulin-stimulated glucose utilization as measured by the euglycaemic clamp [38]. Thus, 2-h plasma insulin levels can be considered at least a qualitative estimate of insulin resistance. The other limitation of our study was that the OGTT was performed only once both at baseline and at follow-up and the glucose tolerance status of the participants is based on a single test at each time point. It is known that repeated OGTTs give a more accurate estimate of glucose tolerance status than a single test [39-41]. This intra-individual variation in glucose tolerance tends to attenuate associations with other variables. Despite this, we found that cardiovascular risk factors were associated with subsequent development of diabetes.

In conclusion, our study demonstrated that cardiovascular risk factors are predictors of diabetes in elderly subjects and the risk of diabetes increases by clustering of risk factors related to insulin resistance (IGT, hypertriglyceridaemia, low HDL cholesterol level, and hypertension). Since the 2-h plasma insulin level parallelled the increase in the risk of diabetes it is probable that the mechanism explaining the association between clustering of cardiovascular risk factors and the risk of diabetes is insulin resistance. However, this does not exclude that cardiovascular risk factors per se may be also risk factors for diabetes.

Acknowledgements. We would like to thank Prof. S.M.Haffner, University of Texas Health Science Center at San Antonio, Texas, for helpful comments in preparing the manuscript. This study was supported by grants from the Academy of Finland and the North Savo Regional Fund of the Finnish Cultural Foundation.

\section{References}

1. Keen H, Jarrett RJ, McCartney P (1982) The ten-year follow-up of the Bedford survey (1962-1972): glucose tolerance and diabetes. Diabetologia 22: 73-78

2. Haffner SM, Stern MP, Mitchell BD, Hazuda HP, Patterson JK (1990) Incidence of type 2 diabetes in Mexican Americans predicted by fasting insulin and glucose levels, obesity, and body-fat distribution. Diabetes 39: 283-288

3. Charles MA, Fontbonne A, Thibult N, Warnet J-M, Rosselin GE, Eschwege E (1991) Risk factors for NIDDM in white population. Paris Prospective Study. Diabetes 40: 796-799

4. Jarrett RJ, Keen H, Fuller JH, McCartney M (1979) Worsening of diabetes in men with impaired glucose tolerance ("borderline diabetes"). Diabetologia 16:25-30

5. King H, Zimmet P, Raper LR, Balkau B (1984) The natural history of impaired glucose tolerance in the Micronesian population of Nauru: a six-year follow-up study. Diabetologia 26: 39-43

6. Saad MF, Knowler WC, Pettitt DJ, Nelson RG, Mott DM, Bennett PH (1988) The natural history of impaired glucose tolerance in the Pima Indians. N Engl J Med 319: 1500-1506

7. Sicree RA, Zimmet PZ, King HOM, Coventry JS (1987) Plasma insulin response among Nauruans. Prediction of deterioration in glucose tolerance over 6 yr. Diabetes 36: 179-186 
8. Lillioja S, Mott DM, Howard BV et al. (1988) Impaired glucose tolerance as a disorder of insulin action. Longitudinal and crosssectional studies in Pima Indians. N Engl J Med 318: 1217-1225

9. Warram JH, Martin BC, Krolewski AS, Soeldner JS, Kahn R (1990) Slow glucose removal rate and hyperinsulinemia precede the development of type 2 diabetes in the offspring of diabetic parents. Ann Int Med 113: 909-915

10. Ohlson L-O, Larsson B, Björntorp P et al. (1988) Risk factors for type 2 (non-insulin-dependent) diabetes mellitus. Thirteen and one-half years of follow-up of the participants in a siudy of Swedish men born in 1913. Diabetologia 31: 798-805

11. Haffner SM, Stern MP, Hazuda HP, Mitchell BD, Patterson JK(1990) Cardiovascular risk factors in confirmed prediabetic individuals. Does the clock for coronary heart disease start ticking before the onset of clinical diabetes - J JAMA 263: 28932898

12. McPhillips JB, Barrett-Connor E, Wingard DL (1990) Cardiovascular disease risk factors prior to the diagnosis of impaired glucose tolerance and non-insulin-dependent diabetes mellitus in a community of older adults. Am J Epidemiol 131: 443-453

13. Papoz L, Eschwege E, Warnet J-M, Richard J-L, Claude J-R (1982) Incidence and risk factors of diabetes in the Paris Prospective Study (G.R.E.A.). In: Eschwege E (ed) Advances in diabetes epidemiology. Elsevier Biomedical Press, Amsterdam, pp 113-122

14. Harris MI, Hadden WC, Knowler WC, Bennett PH (1987) Prevalence of diabetes and impaired glucose tolerance and plasma glucose levels in U.S. population aged $20-74$ yr. Diabetes 36 : 523-534

15. Mykkänen L, Laakso M, Uusitupa M, Pyörälä K (1990) Prevalence of diabetes and impaired glucose tolerance in elderly subjects and their association with obesity and family history of diabetes. Diabetes Care 13: 1099-1105

16. Mykkänen L, Laakso M, Penttilä I, Pyörälä K (1991) Asymptomatic hyperglycemia and cardiovascular risk factors in the elderly. Atherosclerosis 88: 153-161

17. World Health Organization (1985) Diabetes mellitus. Report of a WHO Study Group. (Tech. Rep. Ser. No. 727) World Health Organization, Geneva

18. Hales CN, Randle PJ (1963) Immunoassay of insulin with insulin antibody precipitate. Biochem J 88: 137-146

19. Penttilä IM, Voutilainen E, Laitinen P, Juutilainen P(1981) Comparison of different analytic and precipitation methods for direct estimation of serum high-density lipoprotein cholesterol. Scand J Clin Lab Invest 41: 353-360

20. Siedel J, Hägele EO, Ziegenhorn J, Wahlefeld AW (1983) Reagent for the enzymatic determination of serum total cholesterol with improved lipolytic efficiency. Clin Chem 29:1075-1080

21. Wahlefeld AW (1974) Triglyceride determination after enzymatic hydrolysis. In: Bergmeyer HV (ed) Methods of enzymatic analysis. 2 nd ed. Verlag Chemie Weinheim and Academic Press, New York, pp 1831-1835

22. Norusis MJ (1986) SPSS/PC $+{ }^{\mathrm{TM}}$ for the IBM PC/XT/AT. SPSS, Chicago

23. Agner E, Thorsteinsson B, Eriksen M (1982) Impaired glucose tolerance and diabetes mellitus in elderly subjects. Diabetes Care 5: 600-604

24. Stern MP, Rosenthal M, Haffner SM(1985) A new concept of impaired glucose tolerance. Relation to cardiovascular risk. Arteriosclerosis $5: 311-314$

25. Medalie JH, Papier CM, Goldbourt U, Herman JB (1975) Major factors in the development of diabetes mellitus in 10,000 men. Arch Intern Med 135: 811-817

26. Haffner SM, Valdez RA, Hazuda HP, Mitchell BD, Morales PA, Stern MP (1992) Prospective analysis of the insulin-resistance syndrome (Syndrome X). Diabetes 41: 715-722
27. Ohlson L-O, Larsson B, Svärdsudd K et al. (1985) The influence of body fat distribution on the incidence of diabetes mellitus. 13.5 years of follow-up of participants in the study of men born in 1913. Diabetes 34: 1055-1058

28. Lundgren $\mathrm{H}$, Bengtsson C, Blohme $\mathrm{G}$, Lapidus L, Sjöström L (1989) Adiposity and adipose tissue distribution in relation to incidence of diabetes in women: results from a prospective population study in Gothenburg, Sweden. Int J Obes 13:413-423

29. Larsson B, Svärdsudd K, Welin L, Wilhelmsen L, Björntorp $P_{\text {, }}$ Tibblin $G$ (1984) Abdominal adipose tissue distribution, obesity, and risk of cardiovascular disease and death: 13 year follow-up of participants in the study of men born in 1913. Br Med J 288: 1401-1404

30. Lapidus L, Bengtsson C, Larsson B, Pennert K, Rybo E, Sjöström L (1984) Distribution of adipose tissue and risk of cardiovascular disease and death: a 12 year follow-up of participants in the population study of women in Gothenburg, Sweden. Br Med J 289: 1257-1261

31. Ferrannini E, Barrett EJ, Bevilacqua S, DeFronzo RA (1983) Effect of fatty acids on glucose production and utilization in man. $J$ Clin Invest 72: 1737-1747

32. Lillioja S, Bogardus C, Mott DM, Kennedy AL, Knowler WC, Howard BV (1985) Relationship between insulin-mediated glucose disposal and lipid metabolism in man. $J$ Clin Invest 75: $1106-1115$

33. Boström K, Boren J, Wettesten M et al. (1988) Studies on the assembly of apo-B-100-containing lipoproteins in Hep G2 cells. J Biol Chem 263; 4434-4442

34. Björntorp P (1990) 'Portal' adipose tissue as a generator of risk factors for cardiovascular disease and diabetes. Arteriosclerosis 10: 493-495

35. Haffner SM, Ferrannini E, Hazuda HP, Stern MP (1992) Clustering of cardiovascular risk factors in confirmed prehypertensive individuals. Hypertension 20:38-45

36. Ferrannini E, Buzzicoli G, Bonadonna R et al. (1987) Insulin resistance in essential hypertension. New Engl J Med 317: 350-357

37. Laakso M, Sarlund H, Mykkänen L (1989) Essential hypertension and insulin resistance in non-insulin-dependent diabetes. Eur J Clin Invest 19:518-526

38. Hollenbeck CB, Chen N, Chen Y-DI, Reaven GM (1984) Relationship between the plasma insulin response to oral glucose and insulin-stimulated glucose utilization in normal subjects. Diabetes 33: $460-463$

39. Riccardi G, Vaccaro O, Rivellese A, Pignalosa S, Tutino L, Mancini M (1985) Reproducibility of the new diagnostic criteria for impaired glucose tolerance. Am J Epidemiol 121: 422-429

40. Yudkin JS, Alberti KGMM, McLarty DG, Swai ABM (1990) Impaired glucose tolerance. Is it a risk factor for diabetes or a diagnostic ragbag $\cdot$ ? Br Med J 301: 397-402

41. Feskens EJM, Bowles CH, Kromhout D (1991) Intra- and interindividual variability of glucose tolerance in an elderly population. J Clin Epidemiol 44:947-953

Received: 21 October 1992

and in revised form: 22 February 1993

Professor K.Pyörälä

Department of Medicine

University of Kuopio

P.O.Box 1627

SF-70211 Kuopio

Finland 